\title{
Subject Characteristics Original Result Unit
}

National Cancer Institute

\section{Source}

National Cancer Institute. Subject Characteristics Original Result Unit. NCI Thesaurus.

Code C83400.

The unit of measure for an original subject characteristics result. 